\section{The musical idiot savant}

\section{Dear SirS}

The rare examples of idiot savants with musical ability deserve special mention (Psychiatric Bulletin, August 1990, 14, 475-476). While arithmetical or calendar calculators are remarkable enough, they at least require only one main skill, viz. the ability to memorise and/or calculate using a limited number of mathematical rules. On the other hand, the ability to play, note for note, a tune heard only once or a few times, has several components, each of which is unusual even among people of normal intelligence. The first component is an exceptional auditory memory (perhaps 'eidetic'?) to register and recall the melody and harmony; the second is perfect pitch, whereby the tune can be reproduced not just with the notes in correct relationship to each other, but in the original key; and the third is the motor skills and dexterity necessary to play the tune. The latter skill may be highly developed, as in the case where a piano is played manually while a guitar is strummed simultaneously with the toes.

Even if the idiot savant has no musical creativity to accompany these abilities, they remain an extraordinary group of skills. Their investigation, both psychologically and using neurophysiological and neuroimaging methods as suggested by Schipperheijn \& Dunne, may provide valuable insights into the mechanisms underlying musical abilities in the general population.

Department of Anatomy

St Mary's Hospital Medical School

London W2 IPG

\section{Childhood autism as a disturbance of neuronal migration}

DEAR SIRS

The brief review of Schipperheijn \& Dunne (Psychiatric Bulletin, August 1990, 14, 475-476) of the interesting phenomenon of the idiot savant, offers a number of hypotheses in explanation, among them, intense practice and appropriate reinforcement. A further hypothesis arises from the elegant elucidations of the phenomenon of neuronal migration (Hatten, 1990). If the various manifestations of childhood autism were speculated to be the result of a disruption of these processes of cerebral development, then it is entirely possible that certain layers or regions of the cortex might be more richly endowed than normal with neurones, arrested in their migration. This greater population might then allow a relative "hypertrophy" of the cerebral function subserved by that region.

Quantitative neurocytology (Harper, Kril \& Daly, 1987) might be a means of testing this hypothesis which offers the possibility of examining the cerebral basis for certain cognitive processes.

G. NeIL CONACher

Psychiatric Services

Treatment Centre

Box 22, Kingston, Ontario

K7L $4 V 7$

\section{References}

HARPER, C., KRIL, J. \& DALY, J. (1987) Are we drinking our neurones away? British Medical Journal, 294, 534-536.

HATTEN, M. E. (1990) Riding the glial monorail: a common mechanism for glial-guided neuronal migration in different regions of the developing mammalian brain. Trends in Neurosciences, 13, 179-184.

\section{Patients' ability to give consent}

\section{DeAR SiRS}

I was pleased to read that someone else had realised the importance to psychiatry of recent legal decisions (Jelley, 1990). However, the author fails to develop certain themes which are important to consider in any forthcoming debate. One such theme is the issue of who decides on a patient's ability to give consent and how. Arguably, this should be the province of the psychiatrist. Since psychiatrists' experience of treatment under the MHA has resulted in the development of expertise in assessing the capacity to give consent, it is vital that this expertise is explicitly conveyed to trainees. This will also mean teaching trainees about medical ethics.

Another important theme is that of the conflict between paternalism and patient autonomy. The new Code of Practice incorporates the Law Lords' decision in the case of F v W Berkshire HA, 1989, which allows for treatment of mentally ill patients unable to consent as long as such treatment is believed to be in the patient's best interest. This fails to give guidance on a definition of 'best interests' and also implicitly upholds the 'doctor knows best' school of thought, which many might quarrel with. Further, a Court of Appeal judgement (Wilson v Pringle, 1986) has allowed a defence to the charge of an unlawful battery to be that in acting as he did, the defendant did something which was generally acceptable in the ordinary conduct of daily life (Hirsch \& Harris, 1988). This judgement, like the term 'best interests' is vague and open to abuse. It potentially strengthens the paternalistic camp and must be of concern to those who worry about patients' rights and the risks of our specialty alienating its clients further.

University of Liverpool

L. M. LOVETT

Royal Liverpool Hospital

Liverpool L69 3BX 